\title{
Optimization of Food Acidulant to Enhance the Organoleptic Property in Fruit Jellies
}

\author{
Kesava Reddy C, Sivapriya TVS, Arun Kumar U and Ramalingam C*
}

School of Biosciences and Technology, VIT University, Vellore, India

\begin{abstract}
Citric acid, tartaric acid and malic acids are the commonly used additives in confectionary industries. Their acidity helps in increasing the organo-leptic property of the food product. Other than the flavour, they are also used for their health benefits. They play a major role in boosting renal health, revitalizing skin, fighting free radicals etc. Every individual additive mentioned above has a wide range of health benefits. Initially these additives were used individually to obtain their source fruit's taste. Later, they were mixed to obtain unique flavours. Different level of additive mix gave different level of enhanced taste. This research work aims in appropriate optimization of these additives to provide an enhanced organoleptic property in fruit jelly. The following ratio of citric acid (CA) to malic acid (MA) to tartaric acid (TA) was used in this research work. The ratio was finalized from literature studies. (Sample-S) S1-40:35:25, S2-40:40:20, S3-33.30:33.30:33.30, S4-32.50:50:17.50. Sensory analysis was made to select the best tasting sample and mixed with stabilizers. Sodium citrate, sodium tartrate and a mix of both sodium citrate and sodium tartrate were used to make three samples using the winning proportion of (CA: MA: TA) acids. Sensory analysis was made to select the best among them and they were mixed with fruit pulp finally. Papaya pulp was used in this research work. This final sample was taken for sensory evaluation again to know the feedback on taste of the fruit jelly, which was a positive result where most of the evaluators liked it. The results were analysed using SPSS software. Thus, this research work proves that the organoleptic property of a fruit jelly can be enhanced if the additives were used in an optimized proportion as in sample S1.
\end{abstract}

Keywords: Acidulant; Citric acid; Malic acid; Tartaric acid; Optimization

\section{Introduction}

Food acidulants are commonly used to increase the acidity of the food product. Increasing the acidity of the food helps in preservation, flavour enhancement, anti-pathogenic etc. Two or more acids are combined to produce a unique flavour. Citric (E330), malic (E296) and tartaric acids (E334) are the commonly used additives in food sector. The reason behind their common use are, they are organic. They are obtained from fruits (Citrus fruits, apple, grapes, tamarind etc.) through various extraction and fermentation techniques. Hence they are easily available and economically convenient for the food sectors. Their acidity acts as a preservative. Increased acidic environment in the food kills the microbes and pathogens thus making the food safe [1]. They are Generally Regarded as Safe (GRAS) hence they act as a substitute for the chemical preservatives, since prolonged use of chemical preservative results in health hazards. Citric acid has a very long history in food industries. They are most commonly used and it is one of the conventional food additive too [2]. The health benefits obtained on using these naturally derived food additives are remarkable. Citric acid found to be a very powerful weapon against kidney stone formation. They also help in soothing sore throat, improving mineral absorption, curbing nausea etc. Similarly, tartaric acids are known for their antioxidant and anti-inflammatory properties. Malic acid is good for liver. It is known for its effectiveness in reducing toxicity. Initially, it was used to obtain the taste of their source fruit. Later, food sectors realized their wide range of use when they used different combinations of these additives to produce unique flavours. Tartaric acid is the least used additive when compared to citric and malic acid. It is because, it has a strong flavour which tastes absolute tangy [3]. Also, the cost price of tartaric acid is higher when compared to the other two additives. Still, they are preferred in some food product where strong tangy flavour is required. Appropriate combination of citric, malic and tartaric acid can produce a unique enhanced level of taste. [4,5]. This combination of acidulant has citric acid as a major constituent followed by malic and tartaric acid. They produce an enhanced organoleptic property to the food product and are economically convenient too. This research work focuses on optimising the combination of this additives to find the appropriate ratio of the additives which will produce enhanced organoleptic property to fruit jellies. Combination of additives were arrived from literature studies [6,7].

Initially, four combination of acidulants are arrived and using the combinations, four samples of fruit jellies are produced without any stabilizers and fruit pulp. The samples are taken for sensory evaluation and the winning sample is selected for further addition with stabilizers. Three samples are then produced along with stabilizers and sent for sensory evaluation again. The winning sample is selected and added with papaya fruit pulp. Now, the sample with winning combination of acid and stabilizers are produced with the fruit pulp and again taken for sensory evaluation to know the feedback on their taste. The sensory results are analysed using SPSS software. Papaya is used as a fruit pulp because it is easily available and blends with any type of flavour to produce the similar flavour.

\section{Materials and Methods}

\section{Sample preparation}

Fruit jellies are generally produced by heating appropriate proportion of water, sugar, liquid glucose, stabilizers until it dissolves.

${ }^{*}$ Corresponding author: Ramalingam C, School of Biosciences and Technology, VIT University, Vellore, India, Tel: +91-416-220-2574; E-mail: cramalingam@vit.ac.in

Received October 18, 2016; Accepted November 07, 2016; Published November 14,2016

Citation: Reddy CK, Sivapriya TVS, Kumar UA, Ramalingam C (2016) Optimization of Food Acidulant to Enhance the Organoleptic Property in Fruit Jellies. J Food Process Technol 7: 635. doi: 10.4172/2157-7110.1000635

Copyright: (c) 2016 Reddy CK, et al. This is an open-access article distributed under the terms of the Creative Commons Attribution License, which permits unrestricted use, distribution, and reproduction in any medium, provided the original author and source are credited. 
It is then followed by adding fruit pulp. It is cooked up to $90^{\circ} \mathrm{C}$. Then pectin and permitted colour solutions are added. The total solids will be checked by refractometer till $80-81$ TS achieved. Steam is cut off after this stage and permitted flavours, acids are added and mixed. It is then allowed to cool and thus jellies are produced [8]. We followed the similar procedure to prepare our sample.

Citric (E330), malic (E296) and tartaric acid (E334) were purchased from Tirumalai chemicals. Four combinations of these additives were made based on literature studies [6,7]. Four samples of fruit jellies are produced using the arrived combination of additives in a hygienic manner. The combinations are represented in Figure 1.

Four samples were taken for sensory analysis. The winning sample's combination is used to produce fruit jellies with stabilizers. Sodium citrate (E331), sodium tartrate (E335) were used. Three samples of fruit jellies are produced using the winning additive combination and stabilizers. The three stabilizers used are represented in Figure 2. Three sample of fruit jellies were taken for sensory analysis. The winning sample's combination of acidulants, stabilizers are used to produce the final jelly with the fruit pulp. Papaya pulp is used in this research work as they are easily available and blends with any flavour to produce the desired flavour. Fresh papaya pulp is obtained by extracting from ripened fruit $.750 \mathrm{mg}$ of papaya pulp is used per gram of the jelly. Thus, every single fruit jelly produced, contains $60 \mathrm{mg}$ of acidulants, $15 \mathrm{mg}$ of stabilizers, $750 \mathrm{mg}$ of pulp and other additives. The samples are assessed for physical characteristics (Like, shape, appearance, colour and moisture content of the fruit jelly), chemical characteristics (Like, water activity, reducing sugars, $\mathrm{pH} /$ acidity, and sucrose content), and

\section{COMBINATION OF ADDITIVES USED}

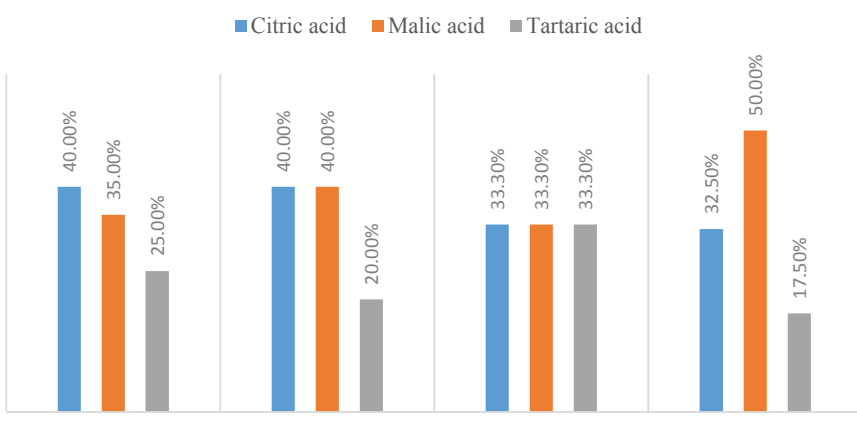

Figure 1: Combination of additives used.

\section{PERCENTAGE OF STABILIZERS USED}

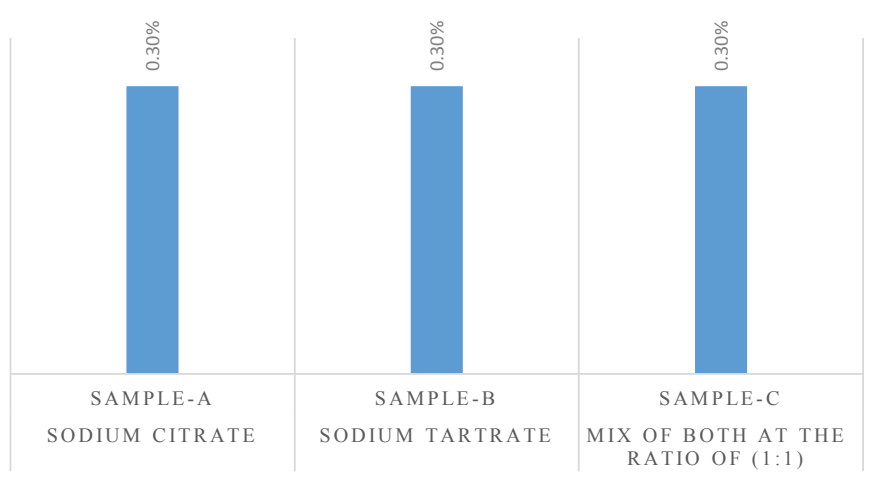

Figure 2: Percentage of stabilizers used in the samples. micro characteristic (Using Total Plate Count, Yeast and Mould count, general pathogen analysis) as per FSSA procedure before sending it to sensory analysis.

\section{Sensory analysis}

Three sensory analysis was made. One for the samples with acidulants, one with acidulants + stabilizers and one with acidulant + stabilizer + papaya pulp. Sensory analysis was made by 80 volunteers from VIT University. Volunteers were from varying age group (ranging from 18-55 years old) and were asked to analyse upon their consent. They were asked to taste the samples and rate their characteristics (Like, texture, flavour and overall acceptance.) on a five point hedonic scale as shown in Table 1 [9].

\section{Statistical analysis}

The test data generated from the sensory evaluation was subjected to find the mean value, standard deviation, analysis of variance (ANOVA) and the Tukey test for multiple comparison and hence the homogenous subset from the Tukey test to find the highest value of alpha. These were performed to identify difference between the means of the samples and to find the difference at probability level $\mathrm{p}<0.05$ were considered to have difference between the variance in the population, also to establish a significant difference in the sample under sensory analysis. Then Tukey honesty significant difference (HSD) was calculated, to establish which sample exhibited significant difference from one and another [10]. For analysis of the data SPSS statistics 20.0 software was used.

\section{Results and Discussion}

\section{Statistical analysis of trail-1 results over flavour}

The proximate composition of the flavours in the samples for the trail test are Sample A (citric acid-40\%, Malic acid-35\%, Tartaric acid25\%) Sample B (Citric acid-40\%, Malic acid-40\%, Tartaric acid-20\%) Sample C (Citric acid-33.3\%, Malic acid-33.3\%, Tartaric acid-33.3\%) Sample D (Citric acid-32.50\%, Malic acid-50\%, Tartaric acid-17.5\%) (Table 2). So here the null hypothesis is rejected, the p-value as Sig. is less than that of the significance value 0.05 which concludes that there is a difference between the variances in the population. It shows there is significant difference in the flavour combination of among at least three of the four formulations.

\section{Homogeneous subsets}

From the first trail, we conclude that the panellist preferred Sample A (Citric acid- $40 \%$, Malic acid-35\%, Tartaric Acid-25\%) over the other samples (Table 3).

Statistical analysis of trial-2 results over stabilizer from the optimized flavour sample: Stabilizers as mentioned in the literature has an influence on the sensory attribute of flavour on the fruit jellies, so three different stabilizer sodium citrate, sodium tartrate and combination of both sodium citrate and tartrate and coded as (T1, T2, T3) were used on the optimized sample from flavour trail test (Table 4).

\section{Conclusion}

From the Table 4, it can be concluded that the ANOVA result shows a higher significance value than 0.05 , which shows there isn't any significance difference in the sample when the stabiliser is added. This proves that the stabilisers did not influence as of sensory and texture is concerned. And the Tukey test confirms that T3 (combination of sodium citrate and sodium tartrate) was preferred more by the population than the rest (Table 5). 
Citation: Reddy CK, Sivapriya TVS, Kumar UA, Ramalingam C (2016) Optimization of Food Acidulant to Enhance the Organoleptic Property in Fruit Jellies. J Food Process Technol 7: 635. doi: 10.4172/2157-7110.1000635

\begin{tabular}{|c|c|}
\hline Ratings & Comment \\
\hline 5 & Excellent \\
\hline 4 & Good \\
\hline 3 & Moderate \\
\hline 2 & Fair \\
\hline 1 & Poor \\
\hline
\end{tabular}

Table 1: Hedonic scale rating and their interpretation

\begin{tabular}{|c|c|c|c|c|c|}
\hline \multicolumn{1}{|l|}{ ANOVA } & $\begin{array}{c}\text { Sum of } \\
\text { Squares }\end{array}$ & Df & Mean Square & F & Sig. \\
\hline Between Groups & 7.057 & 3 & 2.352 & 2.679 & 0.047 \\
\hline Within Groups & 242.314 & 276 & 0.878 & - & - \\
\hline Total & 249.371 & 279 & - & - & - \\
\hline
\end{tabular}

Table 2: ANOVA results for trail-1.

\begin{tabular}{|c|c|c|c|}
\hline \multicolumn{4}{|l|}{ Tukey's HSD ${ }^{a}$} \\
\hline \multirow{2}{*}{ Acid combinations } & \multirow{2}{*}{$\mathbf{N}$} & \multicolumn{2}{|c|}{ Subset for alpha $=0.05$} \\
\hline & & 1 & 2 \\
\hline Sample D & 80 & 3.63 & - \\
\hline Sample C & 80 & 3.87 & 3.87 \\
\hline Sample B & 80 & 3.91 & 3.91 \\
\hline Sample A & 80 & - & 4.07 \\
\hline Sig. & & 0.274 & 0.587 \\
\hline
\end{tabular}

Table 3: Turkey HSDa result for trail-1.

\begin{tabular}{|c|c|c|c|c|c|}
\hline \multicolumn{7}{|l|}{ ANOVA } \\
\hline & $\begin{array}{c}\text { Sum of } \\
\text { Squares }\end{array}$ & Df & Mean Square & F & Sig. \\
\hline Between Groups & 2.155 & 2 & 1.077 & 1.298 & 0.275 \\
\hline Within Groups & 169.275 & 204 & 0.830 & - & - \\
\hline Total & 171.430 & 206 & - & - & - \\
\hline
\end{tabular}

Table 4: ANOVA results for trail-2.

\begin{tabular}{|c|c|c|}
\hline \multicolumn{3}{|l|}{ Tukey HSDa } \\
\hline \multirow{2}{*}{ Formulation of stabilizers } & \multirow{2}{*}{$\mathbf{N}$} & Subset for alpha $=0.05$ \\
\hline & & 1 \\
\hline T1 & 80 & 3.57 \\
\hline $\mathrm{T} 2$ & 80 & 3.72 \\
\hline T3 & 80 & 3.81 \\
\hline Sig. & & 0.253 \\
\hline
\end{tabular}

Table 5: Turkey HSDa results for trail-2.

\section{OVERALL ACCEPTANCE OF FRUIT JELLY}

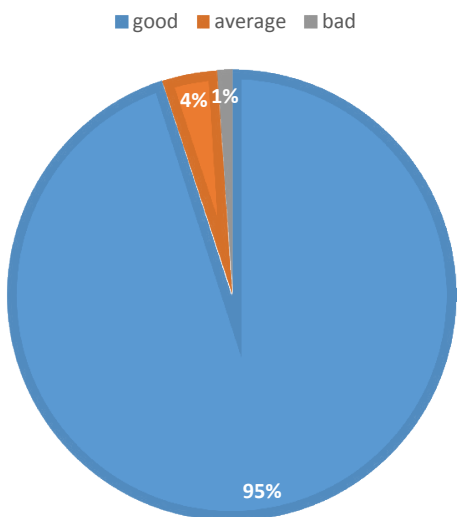

Figure 3: Pie-chart representing the overall acceptance of fruit jelly.
Trail-3 was made using the sample prepared with the composition of the winning sample of trail-1 and trail-2. Thus, it was made with $40 \%$ of citric acid, $35 \%$ of malic acid, $25 \%$ of tartaric acid and a mix of both sodium citrate and sodium tartrate as stabilizers mixed with papaya pulp. About $95 \%$ of the panellist rated the sample as good. This is represented in Figure 3.

From Figure 3, we can interpret that our sample with $40 \%$ citric acid, 35\% malic acid, 25\% tartaric acid, mixed stabilizers of sodium citrate and sodium tartrate along with papaya pulp has been liked by $95 \%$ of the panellist (on a total of 80 people). They rated this sample as GOOD. We have got a positive result and thus we can conclude that the above-mentioned ratio of acidulants produced enhanced organoleptic property of the fruit jelly in an economically convenient way than the generally used additives to obtain such enhanced organoleptic property.

\section{References}

1. Humayun A (2014) Effect of citric and malic acid on shelf life and characteristics of orange juice. Int J Pharmaceutic Sci 6: 117-119.

2. Tammy Nash J (2012) Acids in confections. The Manufacturing Confectioner.

3. Maria MT, Lues JR (2010) Organic acids and food preservation. CRC Press Inc, Boca Raton, USA.

4. Ahmed H, Chandan KG, Mukund M, Sumeet S, Chidambaram R (2013) The effect of citric and malic acid additives on the storage stability and sensitive parameter in lemonade. Res J Pharmaceutic Biol Chem Sci 4: 1671-1679.

5. Malundo TMM, Shewfelt RL, Ware GO, Baldwin EA (2001) Sugars and acids influence flavour properties of mango. J Amer Soc Hort Sci 126: 115-121.

6. Jai Prakash S, Satish Kumar S, Ruchika C, Gaurav P, Alok P, et al. (2014) Optimisation of common acidulant (fruitaric acid) to enhance organoleptic quality and shelf life of fruit juices. Int J Pharmaceutic Sci 46: 269-273.

7. Saha P, Jai Prakash S, Sumeet S, Ahmed H, Ramalingam C (2013) Optimisation of citric acid and malic acid to enhance flavor and shelf life of mango juice. Chem Pharmaceutic Res 5: 90-95.

8. Catharina YW, Liu K, Yao-Wen H (1999) Asian foods: science and technology. Technomic publishing company.

9. Morten CM, Thomas BC, Gail V (1991) Sensory evaluation techniques. CRC Press Inc, Boca Raton, USA.

10. Abdi H, Williams LJ (2010) Tukey's honestly significant difference (HSD) test Encyclopaedia of Research Design, Sage, Thousand Oaks, CA. 